\title{
Regional Diversities and Movie Title Translation
}

\author{
Liu Qi \\ Foreign Language Department, Xiamen University Tan Kah Kee College, Zhangzhou, 363105 \\ wwy2zoe@163.com
}

Key words: movie title, translation, regional diversities

\begin{abstract}
This paper analyzes the reasons resulting in the disunity of the movie title translations in Hong Kong, Taiwan and Mainland from the angle of culture. It points out that the reasons lie in three aspects: ideological differences, linguistic differences and different translation purposes. Firstly, this paper expresses the present researches on movie title translation, and finds out the area which can be further studied. Secondly, this paper respectively proves that the differences in ideology, linguistic habits and translation purposes cause the disunity of the movie title translations in Hong Kong, Taiwan and Mainland under the guide of the theory of culture, by comparing the different cultural backgrounds in these regions with plenty of the translation examples. The last part concludes the discussion along with the confession of the weaknesses involved in this research.
\end{abstract}

\section{Introduction}

A film title is an important part of a film and has its unique functions. It conveys the most important information about the film to the audience as well as serves as a promotion of the film. Film title translation seems to be an easy task, but actually it is a complicated and complex task. It has its own linguistic, aesthetic and cultural features. All these aspects are worth the translator's attention. However, as a branch of non-literary translation, the translation of English movie titles, like many other forms of non-literary translation, has not yet received due attention despite their importance. Peter Newmark has called on the translators to bring their attention to "two underplayed aspects of translation" (45), one of which is "the approach to non-literary translation" (45). Nida also called for more attention to exploring new fields in translation (Wu 11-12). Furthermore, it is undeniable that the research of the reasons resulting in the disunity in the renderings in Hong Kong, Taiwan and Mainland is very important to the movie and culture communication. Apart from it, digging out more hidden reasons, it will promote in greater degree the mutual understanding of these regions and it is even more helpful to our unification of Chinese whole nation.

Movie titles are always the first thing that the audience comes to know about new movies. Thus a right choice of movie title translation is of great importance to the successful release of a movie. And in recent years, with the advent of the globalization, there are increasing exchanges between Mainland, Hong Kong and Taiwan in many aspects. So it is useful and practical for translators to pay attention to the different renderings of the English movie titles in these regions. Translation workers should adhere to exploring a new field and find the deep reasons hiding behind such phenomena. The task is tough but it is of great importance to the mutual understanding during the exchanges among these regions, and it also can promote the movie communications between the whole China and the western countries if the translators in Mainland, Hong Kong and Taiwan can learn from each other and produce better movie title translations to do a more excellent and successful popularization for the movie.

Therefore, firstly, in the paper, the reasons for the disunity in cultural aspect are examined, mainly in two ways: ideological influences and ethical influences. Secondly, a research in linguistics is done through the introduction of the linguistic characteristics of the English movie titles, and then the analysis of the characteristics of the translations in Hong Kong, Taiwan and Mainland respectively. Moreover, the problem from the perspective of the translation purposes is studied, either. In conclusion, regional diversities are regarded as an important cause for the phenomena of different 
movie title translations in Mainland, Hong Kong and Taiwan. After understanding it, the translators in these regions can produce better movie title translations. For that, they can contribute more to the movie communications between China and the English countries.

\section{Ideological Differences and Movie Title Translation}

\subsection{Historical Influences on the Title Translation.}

As it's known, Hong Kong and Taiwan are parts of China since the ancient times. They are the same to the mainland. No one can deny the fact. But for a long time, people of Hong Kong and Taiwan have lived under a special social system different from that of the mainland. They still belong to the capitalist society where the spirit Money is God is popular in every corner. People's life speed there is so high that if one lags behind one second, one would be left exceedingly far away. Comparing to the rich inside quality, they respect business and entertainment more. So it is credible that their culture is more and more considered as constant culture.

A Japanese scholar once did a survey about people's lack of sense of safety in Hong Kong and Taiwan. They live on the islands which face the mainland on the other side of the sea, and for quite a long time, most of them have been separated with their relatives. In addition, during the past decades, both of Hong Kong and Taiwan had experienced the horrible economic crisis. People feel frightened, scared and are afraid of losing what they own again, so they work hard, strive for the future, and vitalize the economy constantly. Therefore, it is not odd that when the movie title translations there always express a sense of commerce.

Along these years, the governments in Hong Kong and Taiwan continuously have advocated to conserve the traditional Chinese culture in their own regions. However, with the development of the globalization, on the one hand they have the desire to keep up with the global pace and join the international club, on the other hand they sincerely adore the tradition and try to boast of fully commanding of the traditional Chinese culture, whereas gradually they lose the ability to judge what is traditional and what is international. For this reason, some movie title translations seem to be strangely enough. Despite it, there are still some good translations which outweigh the mainland ones in revealing the movie story, such as Meet The Parents is titled Men Dang Fu Bu Dui (shows the conception of Men Di in the Chinese tradition) in Taiwan. As good as it gets is translated as Ai Zai Xin Kou Nan Kai in Hong Kong.

In contrast, most of the people in Mainland hold the view of "zhong yong" and "he xie". The so-called "zhong yong" means a kind of world view which comes up with the idea that sticking to the middle of the road is the proper way to live. It is the core of the Chinese traditional values. As early as the times of Confucius, it has been very popular and it is also the central part of Confucianism. The so-called "he xie" means harmonious. Chinese people usually adore harmony and peace. In no matter what events, people love happy endings. Towards everything, they seldom stand on the extreme side, and are afraid of hurting others' feelings or benefits. What they always chase is "jie da huan xi" (Everyone is happy) and "zuo you feng yuan" (be able to achieve success one way or another; gain advantage from both sides). The viewpoint has influenced people's life and behavior for so long years that such idea has formed an indispensable part of people's character in China. We can also notice the impact of that ideology on the movie title translation in Mainland. So that is why most translators in Mainland are more loyal to the original title, and there are less bewildering words which are more used in Hong Kong and Taiwan in order to attract the audience's attention. Owing to that, the techniques the translators of the mainland choose appear to be fixed, safe and tedious, not like free translations in Hong Kong and Taiwan.

\subsection{Ethical Influences on the Title Translation.}

In the past one hundred years beyond 1997, Hong Kong had been occupied by the British Empire. Up to now, Taiwan has been controlled by the capitalist power. Hong Kong and Taiwan step into the capitalist world from the feudalist society without experiencing contradictory struggles like Mainland. 
They make good use of the historical opportunities to develop themselves and have greatly changed in every social aspect, even their ethical views.

Both of Hong Kong and Taiwan are developed. In these regions, people frankly state their opinions, boldly speak out their desires, and realize their dreams without any hesitation. They do not think there is any necessity to conceal their emotions and it is not shameful to talk about their desires, such as love, sex, political power, and money. What is more, with the development of the economy and with the advent of the globalization, people there gradually accept the conceptions and values of those developed countries in the western world. They become more open and braver to not only express their desires but also find all sorts of ways to satisfy their desires. So that is the reason why there are so many entertainment industries and recreations in Hong Kong and Taiwan. Accordingly, it is not strange that in the movie title translations of Hong Kong and Taiwan, there are a lot of inflammatory words so as to draw people's eyeballs. Otherwise, if the title is not horrible enough or not fanciful, people will not spend time on it and they would rather work for a longer time to earn money.

While in the minds of people in Mainland, as a human being, we should control our feelings, even oppress them. Showing off is not a glory. Obedience is the virtue. Every people should absolutely obey the traditional views which are thought perfect by most of the people. Rare people dare say something about their inner hearts, because they are anxious about the criticism from the rest of the people, not mention the fight for the desires. They think it is not elegant to talk about the desires which are considered to be private affairs. Therefore, in most of the movie title translations in Mainland, translators never use some emotional words and try to avoid suggesting something related to sex, violence and so on.

\section{Linguistic Differences and Movie Title Translation}

\subsection{Linguistic Characteristics of English Movie Titles.}

Movie titles, with the function of providing information about the story for the audience, often summarize the main plot, reveal the theme or offer some clue. And English movie titles, conditioned by some features of English, usually demonstrate the following characteristics:

\subsubsection{Brief and Concise.}

English movie titles are usually concise and to the point. More than $70 \%$ of them consist of only one or two key words (Pronouns and all the lexical words are included), such as Man in Black, Minority Report. Short sentences, such as It Happened One Night, Everyone Says I Love You and the like, occasionally appear in movie titles.

Despite the briefness of English movie titles, they are capable of carrying much information and can be remembered easily, because nearly $90 \%$ of them are made up of nouns or noun phrases. Only a marginal part is left to verb phrases like Catch Me If You Can, Kill Bill.

\subsubsection{More Descriptive than Allusive.}

Peter Newmark divides titles into two categories: descriptive and allusive. "Descriptive titles describe the topic of the text directly while allusive titles have some kind of referential or figurative relationship to the topic" (Newmark 53). There are more descriptive movie titles than allusive ones. Almost for every six titles, there is only one allusive.

From a descriptive title, the audience can easily get a general idea of a story. Maid in Manhattan, a modern Cinderella-style story, tells of a beautiful mistake and an unexpected romance that have fallen on a hotel maid. Gangs of New York narrates a story in the New York City of the middle 19th century about a young man who seeks vengeance against the man who killed his father in a conflict between the powerful Manhattan gangs.

As for an allusive title, the audience cannot tell the main plot of the movie from it, but it necessarily bears some relationship with the story. Take True Lies for example. The original title, an oxymoron, vividly depicts the double life of a CIA agent starred by Arnold Schwarzegger. Another example of this sort is The Hours, which has been rendered into Xiao Shuo Ren Sheng, Shi Shi Ke Ke and Liu 
Guang Sui Ying. The movie is made up of stories of three women, living in different times, and their stories are strung together by one novel - Mrs. Dalloway.

\subsubsection{Heroes' or Heroines' Names as Titles.}

In a Chinese movie, usually only heroes or VIPs are privileged to have their names as movie titles. But an English movie does not always go this way. Even if its heroes or heroines are ordinary people, it would have their names as titles - Evelyn, Dr. Dolittle, Stuart Little, Thelma and Louis, and even when its heroes or heroines are negative characters, it will do so as well, such as Hannibal, Frankensten, and Goldfinger.

\subsubsection{Settings as Titles.}

English movies often choose settings, i.e. where the story occurs, as titles, such as Air Force One, Pearl Harbor, Titanic, Battleship Potemkin, Dogville, Grand Hotel and Barbarshop. By providing a special circumstance for the development of the story, these settings, grand or humble, are usually significant to the theme of the story or have profound meanings for the heroes or heroines.

The movie, Ararat, was released in 2002 and directed by Canada's Atom Egoyan, the son of an Armenian immigrant family. The Ararat, the highest mountain in Armenia, is a symbol of the noble spirit of the Armenian nation. The director chooses it as his movie title because it was the witness of Armenia's miserable history during 1915 when more than 1.5 million Armenians were massacred by the Turks, which is still denied by today's Turkish government.

\subsection{Influences of Readability and Choices of Words.}

Movie title is used to provide related information about the story for the audience, so its translation should be always faithful to the story of the movie. Here faithfulness cannot be understood as full respect for the original title. If the SL title adequately describes the content, and is brief, then leave it. The translation of True Lies into Zhen Shi De Huang Yan is fine. Otherwise, the translator can discard the original for the sake of faithfulness to the story, such as The Mask. Of course, it is perfect to be faithful to both. But if it cannot be made at once, faithfulness to the original title then has to give way to faithfulness to the story.

"Due to cultural differences between the SL and the TL, some English movie titles will inevitably contain something peculiar to its own culture" (Pearl 3). Some mistranslations are caused by misunderstanding of cultural information in original titles. Therefore, the translator should be aware of such cultural information, fully grasp the real meaning of it, and properly translate it into the TL.

In 1999, an American movie Double Jeopardy was mistranslated as Shuang Chong Yin Mou. However, in English, Double Jeopardy, a law term, means the second litigation to the criminals. So here, it can not be understood in that way.

American Beauty's title translation is Mei Guo Li Ren, when the movie is brought in. Actually, American Beauty in English is a flower name and what it symbolizes is the rose appearing many times in the movie.

The translation of movie titles should also take into account both commercial and aesthetic effects. On the one hand, the more attractive the title is, the more audience the movie may have and the more profits it will make. But on the other hand, the title should not go too far to the point of fanciness and vulgarity to call the attention of the audience; instead, it should offer an aesthetic feeling within the understanding of most ordinary people. A well-translated title should be a perfect combination of attractiveness and quaintness, and capable of achieving both commercial and aesthetic effects.

For example, the famous American movie called Gone with the Wind is adapted from a book with the same title Gone with the Wind, and the Chinese title of the book is Piao. But Piao is too elegant and abstract for a movie and the one-character title is not so powerful and easy to read aloud in Chinese as the four-character phrase Luan Shi Jia Ren, a most frequently-used pattern in Chinese.

We can also take anther movie Mission: Impossible for example. It has two other renderings: Zhi Ye Te Gong Dui (HK) and Bu Ke Neng Wan Cheng De Ren WU (Taiwan). But neither leaves a deeper impression on the audience than does Die Zhong Die (Mainland), the three-character title, brief but forceful, full of tension and suspense. The mainland version has been widely praised for its originality and novelty. 


\subsubsection{Hong Kong and Taiwan: Preference of Dialects.}

Owing to the special social system and the distinct geographical characteristics, languages people use in the everyday life in Hong Kong and Taiwan have not confirmed with that of the mainland. It is reasonable that it is easier for people to communicate in their dialects, no matter in Hong Kong, Taiwan, even in many provinces of the mainland. However, "the importance of dialects in Hong Kong and Taiwan can balance that of Putonghua in the mainland" (Liang 8). A good number of TV programs and newspapers have been created in dialects, far beyond just existing in people's common activities. Accordingly, the movie companies are apt to use dialects when they translate the English movie titles, and thus they can attract more audience's attention and have greater impact in their own regions. Take some movies for example. The Cable Guy is translated as Xian Gui Sui Ren, and The Princess Diaries as Zou Lao Qiao Gong Zhu. The most famous should be The One. It is translated into Zui Hou Yi Qiang in Hong Kong.

Frankly speaking, if the people know Cantonese or Southern Fujian Dialect, they can understand the movie titles, guess the main idea of the story and get fun from it; conversely, if the people know English and Mandarin, but don't know the dialects, they must get confused and puzzled by this kind of translation. For example, He Bi Pian Pian Wan Xie Wo is the title translation of Adaptation, and Pay It Forward's translation is La Kuo Ai De Ren.

\subsubsection{Mainland: Pursuit of Beauty of Language.}

In Mainland, most of the translators have received good education, have followed strict translating styles, and have been greatly influenced by the broad magnificent landscape, the long history of China, and rich culture of ancient times. They emphasize the importance of the beauty of language, including the choice of the word, the significance of the choice, and the relation between the original title and the title translation, when they do the movie title translation. For that reason, they have produced a good number of outstanding movie title translations. Take an old American movie The Waterloo Bridge for example. This is the mainland version which can be considered as a typical model. If the title is directly translated, then it would turn out to be Hua Tie Lu Qiao which seems to relate to the place where Napoleon was defeated. Actually, the movie tells about a love tragedy which has no relation to Napoleon. Translators in Mainland retain "qiao" in the original title, properly convey the story of the movie, and offer the translation a sense of tragic beauty.

\section{Translation Purposes and Movie Title Translation}

\subsection{Hong Kong and Taiwan: Mainly for Commercial Interests.}

Hong Kong and Taiwan is same to each other in some aspects. Both of the two places are developed and prosperous. The movie industry has grown quickly in Hong Kong and Taiwan in recent years. The functions of the movies no longer only lie in cultural communications for the whole world, but entertaining the public. So under such circumstances, they pay more attention to the commercial effects. The more attractive the title is, the more audience the movie may have and the more profits it will make. For that reason, when the translators do the movie title translations in Hong Kong and Taiwan, they spent more time in creating the titles covered by the commercial coats.

\subsection{Mainland: Mainly for Cultural Communication.}

It is far enough for a person to just learn the culture of his or her own country. In that way, people's mind will be definitely bounded. Because each country is only a part of the world, and people's life and knowledge in each country is also only a part of the culture in the world, it is exceedingly necessary to communicate with other countries in order to rich ourselves then we can advance more. It is not the end. We not only need to understand the culture of other countries, but also need to go out of our own country with our own culture to let the world understand us and win more supporters of our country then we can more easily deal with both of our friends and enemy.

Movie builds a concrete bridge among the countries in the world. Each movie is based on the culture of its country or other countries and to some extent truly reflects the history, geography, ideology, and reality of one society and the like. People can appreciate the exotic feelings brought by 
the movies and broaden their horizons according to it. And the governments in the mainland still emphasize that movie is access to the national education of the native values and the world view; consequently, translations of the movie titles, from the English countries in particular, are usually strict and cautious. They take into account both of the commercial effects and the aesthetic feelings. So it is reasonable that the movie title translation in Mainland seems more graceful and all classes of the people can enjoy the beauty of the translation, regardless of their age, gender, profession and so on.

\section{Conclusion}

From the above analysis we can see that English film title translation is meaningful and challenging, and worth discussing with no doubt. The movie title is always short in form and seems to weigh lighter, but it is rich in meaning and has its unique functions. In many people's minds, movie title translation is simple and easy, actually it is complicated and problematic nevertheless. A properly-translated English movie title should be concise, condensed and compact, which can grip the audience's eyeballs at the first sight, stimulate their association with the plot, reveal the theme or offer some clues. So they indeed deserve translators' careful investigation, consideration and exploration. However, the majority of the researches still stay superficially on the methods and techniques employed in the movie title translation. Few translators take notice of the differences of the movie title translation among Mainland, Hong Kong and Taiwan from the cultural perspective, despite its importance in mutual communications.

This paper has discussed the present different movie title translation versions existing in Hong Kong, Taiwan and Mainland and continued to study the reasons behind the mask. Firstly, it expresses the present state of the English movie title translation, and finds out the area which can be further studied. Secondly, this paper shows the reasons of the disunity of the movie title translation in Hong Kong, Taiwan and Mainland, mainly in three aspects, cultural differences, linguistic differences and translation purposes. All that guides us how to solve the problem in translation, above all we should pay special attention to the movie title translation and at the same time we should make some adjustment depending on different cases so that the translations will be more suitable for the target language.

\section{References}

[1]. Gentzler, Edwin. Contemporary Translation Theories. Shanghai: Shanghai Foreign Language Education Press, 2003.

[2]. Liang Lili. "The Relations between Cantonese and Hongkong Culture". Dialect, 1997 (3): 6-7.

[3]. Newmark, Peter. A Textbook of Translation. Shanghai: Shanghai Foreign Language Education Press, 2001.

[4]. Nida, Eugene A. The Theory and Practice of Translation. Shanghai: Shanghai Foreign Language Education Press, 2004.

[5]. Pearl, Stephen. "The Hong Kong Linguist: Mistranslation and the Media". Journal of the Institute of Linguists Hong Kong Regional Society. 1995 (15): 34-42.

[6]. Wu Min. "Brief Introduction of Movie Title Translation". Chinese Translators Journal, 1995 (5): 23-27. 